\title{
Correction to: Reliability and validity of the Pittsburgh Sleep Quality Index in breast cancer patients
}

\author{
Filipa Fontes $^{1} \cdot$ Marta Gonçalves $^{1,2} \cdot$ Susana Maia ${ }^{2} \cdot$ Susana Pereira ${ }^{1,3} \cdot$ Milton Severo $^{1,4} \cdot$ Nuno Lunet $^{1,4}$
}

Published online: 3 June 2019

(C) Springer-Verlag GmbH Germany, part of Springer Nature 2019

\section{Correction to: Support Care Cancer (2017) 25:3059-3066}

https://doi.org/10.1007/s00520-017-3713-9

There is a typo in the Funding reference cited in the paper.

Where it reads:

PTDC/DTP-EPI/7283/2014

It should read:

PTDC/DTP-EPI/7183/2014

Publisher's note Springer Nature remains neutral with regard to jurisdictional claims in published maps and institutional affiliations.

The online version of the original article can be found at https://oi.org/ $10.1007 / \mathrm{s} 00520-017-3713-9$

Nuno Lunet

nlunet@med.up.pt

1 ISPUP - EPIUnit, Universidade do Porto, Rua das Taipas, 4050-600 Porto, Portugal

2 Centro de Medicina do Sono-Hospital CUF Porto, Estrada da Circunvalação, 4100-180 Porto, Portugal

3 Instituto Português de Oncologia do Porto, Rua Dr. António Bernardino de Almeida, 4200-075 Porto, Portugal

4 Departamento de Ciências da Saúde Pública e Forenses e Educação Médica, Faculdade de Medicina, Universidade do Porto, Al. Prof Hernâni Monteiro, 4200-319 Porto, Portugal 